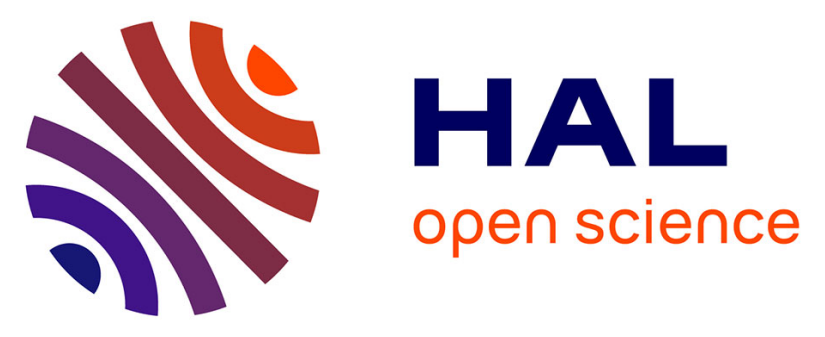

\title{
Spectral Distributions of Chirped Pulsed Four-Wave Mixing in a Photonic Crystal Fiber Measured by Dispersive Fourier Transform Method
}

Coralie Fourcade-Dutin, Paul Robert, Romain Dauliat, Raphaël Jamier, Hector Munõz-Marco, Pere Pérez-Millan, John M Dudley, Hervé Maillotte, Philippe Roy, Damien Bigourd

\section{To cite this version:}

Coralie Fourcade-Dutin, Paul Robert, Romain Dauliat, Raphaël Jamier, Hector Munõz-Marco, et al.. Spectral Distributions of Chirped Pulsed Four-Wave Mixing in a Photonic Crystal Fiber Measured by Dispersive Fourier Transform Method. Advanced Photonics Congress-Nonlinear Photonics,, OSA, Jul 2020, Montreal (virtual ), Canada. NpTu1E. 4, 10.1364/NP.2020.NpTu1E.4 . hal-02965784

\author{
HAL Id: hal-02965784 \\ https://hal.science/hal-02965784
}

Submitted on 13 Oct 2020

HAL is a multi-disciplinary open access archive for the deposit and dissemination of scientific research documents, whether they are published or not. The documents may come from teaching and research institutions in France or abroad, or from public or private research centers.
L'archive ouverte pluridisciplinaire HAL, est destinée au dépôt et à la diffusion de documents scientifiques de niveau recherche, publiés ou non, émanant des établissements d'enseignement et de recherche français ou étrangers, des laboratoires publics ou privés. 


\title{
Spectral Distributions of Chirped Pulsed Four-Wave Mixing in a Photonic Crystal Fiber Measured by Dispersive Fourier Transform Method
}

\author{
Coralie Fourcade-Dutin ${ }^{1-2}$, Paul Robert ${ }^{1}$, Romain Dauliat ${ }^{3}$, Raphael Jamier ${ }^{3}$, Hector Munõz-Marco ${ }^{4}$, Pere \\ Pérez-Millan ${ }^{4}$, John M. Dudley ${ }^{1}$, Hervé Maillotte ${ }^{1}$, Philippe Roy ${ }^{3}$, Damien Bigourd*1-2 \\ ${ }^{1}$ Institut FEMTO-ST, Département d'Optique, UMR CNRS 6174 -Université Bourgogne Franche-Comté, 25030 Besançon, France \\ ${ }^{2}$ Laboratoire IMS, UMR CNRS 5218, University of Bordeaux, 33400 Talence, France \\ ${ }^{3}$ Université Limoges, XLIM, UMR CNRS 7252, F-87000 Limoges, France \\ ${ }^{4}$ FYLA LASER SL, Ronda Guglielmo Marconi 12, 46980, Paterna (Valencia), Spain \\ *Corresponding author: damien.bigourd@u-bordeaux.fr
}

\begin{abstract}
Spectral correlation of four wave mixing has been investigated when a chirped pulse pump is injected in a photonic crystal fiber. The dispersive Fourier transform method was used to record single shot spectra and to measure the spectral correlation between the signal and idler components. We show that this method can determine the origin of the FWM in the pump spectrum.
\end{abstract}

\section{Introduction}

Four-wave mixing (FWM) in optical fibers has been extensively investigated in order to amplify ultra-short pulses since it provides large gain-bandwidth [1,2], high gain [2] and very wide tunability. When a chirped pulse pumps a fiber, the instantaneous frequencies of the pump are temporally dispersed and the spontaneous photons are generated with temporal and spectral distributions according to phase-matched FWM relation [3]. In this case, we demonstrated that this configuration allows getting a very large gain bandwidth [2] that enables ultra-short pulse amplification [1]. However, the injected signal requires chirp optimization to match the temporal distribution of the parametric gain spectrum, which depends on both the pump and fiber properties [1]. Therefore, this parametric gain distribution needs to be firstly characterized before being used in a broadband amplifier. In this work, we present a simple approach that allows the spectral and temporal distribution of the instantaneous parametric process to be retrieved using the dispersive Fourier transformation (DFT) method [4]. This powerful technique is significantly simpler to implement compared to pump-probe techniques [5] since it provides the desired information without the need to inject a suitable signal. In our case, we use DFT to measure the spectral correlation between the side bands, which allows us to determine the particular portion of the pump spectrum responsible for generating the FWM.

\section{Experiment and method}

The pump pulse is generated from a mode-locked oscillator (Flint, LightConversion) delivering a train of pulses at $76 \mathrm{MHz}$ with a duration of $80 \mathrm{fs}$ centered at $1030 \mathrm{~nm}$. A part of the oscillator output (around $750 \mathrm{~mW}$ ) seeds an amplifier composed of a volume Bragg grating (VBG) that stretches the pulses to a duration of $\sim 50 \mathrm{ps,}$, an acoustooptic modulator to decrease the repetition rate to $1 \mathrm{MHz}$ and cascaded ytterbium doped fiber amplifiers to increase the average power up to $1 \mathrm{~W}$. The spectral bandwidth at the output of the amplifier is $\sim 9 \mathrm{~nm}$ and is modulated due to self-phase modulation (SPM). The pump pulse is then injected in a 5-meter-long PCF with a zero-dispersion wavelength at $1028 \mathrm{~nm}$. Two FWM lobes are observed and located around 1001 and $1071 \mathrm{~nm}$ for an average power of $18 \mathrm{~mW}$ (Fig. 1.a). Single shot spectra are then recorded by a dispersive Fourier transform set-up with a $11.5 \mathrm{~km}$ long fiber (SMF28) to stretch the output with an approximate chirp value of $\sim-2.54 \mathrm{~nm} / \mathrm{ns}$, a fast photodiode and an oscilloscope with a maximum bandwidth of $12 \mathrm{GHz}$. Figure 1.a displays the superposition of 500 single shot spectra and the averaged curve. Good agreement is obtained with the curve recorded by the optical spectrum analyzer (OSA).

From the single shot spectra, the spectral correlation $\rho\left(\lambda_{1}, \lambda_{2}\right)$ has been calculated between any two wavelengths $\lambda_{1}$ and $\lambda_{2}$ according to 


$$
\rho\left(\lambda_{1}, \lambda_{2}\right)=\frac{\left\langle I\left(\lambda_{1}\right) I\left(\lambda_{2}\right)\right\rangle-\left\langle I\left(\lambda_{1}\right)\right\rangle\left\langle I\left(\lambda_{2}\right)\right\rangle}{\sqrt{\left\langle I^{2}\left(\lambda_{1}\right)\right\rangle-\left\langle I\left(\lambda_{1}\right)\right\rangle^{2} \cdot\left\langle I^{2}\left(\lambda_{2}\right)\right\rangle-\left\langle I\left(\lambda_{2}\right)\right\rangle^{2}}}
$$

where the bracket represents the average over the ensemble. The correlation $\rho$ varies from -1 to +1 indicating intensity fluctuations in the opposite or same directions respectively. For $\rho=0$, no correlation exists between the two wavelengths.

\section{Results and discussion}

Figure 1.b shows the spectral correlation map between 980 and $1090 \mathrm{~nm}$ for an average power of $24 \mathrm{~mW}$ together with the average spectra. The pump spectrum is positively correlated with itself. Similarly, the correlation between two identical FWM bands corresponds to a positive yellow line with $\rho=1$. The signal and idler photons are degenerated with respect to the pump and therefore an anti-correlation between the pump and the two side lobes are observed (black dashed squares) [6]. A zoom view of the spectral correlations between two side bands (black square in Fig. 1.b) is also shown in Fig. 1.c. The black lines are plotted from the photon energy conservation law for several pump wavelengths $\lambda_{\mathrm{p}}$; ie $2 / \lambda_{\mathrm{p}}=1 / \lambda_{1}+1 / \lambda_{2}$. A positive correlation is observed with a specific shape and is mainly between 1070-1075 $\mathrm{nm}$ and $995-1005 \mathrm{~nm}$. From the black line, we deduce that these parts of the bands are generated from the pump spectrum at $1030-1035 \mathrm{~nm}$. A negative correlation value $(\rho=-0.15)$ at around $1082 \mathrm{~nm}$ is also observed. This is attributed to SPM from the pump that decreases the correlation value. According to the FWM relation, it originates from the pump spectrum at $>1035 \mathrm{~nm}$ and correspond to the spectral hole in the pump observed at $1037 \mathrm{~nm}$ (Fig. 1.b-black circle).

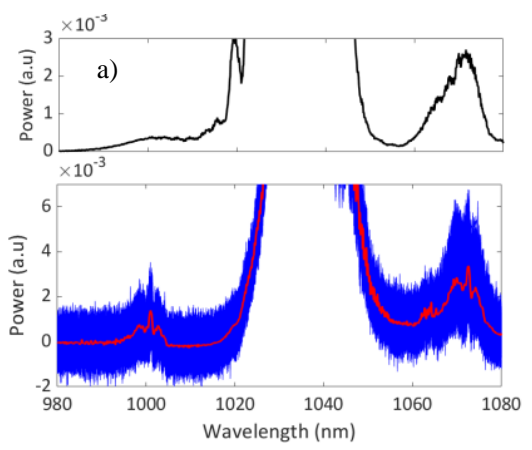

b)

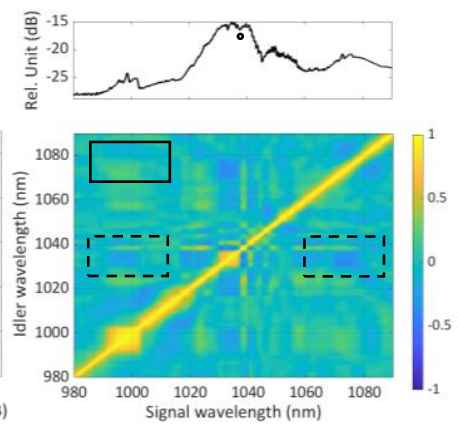

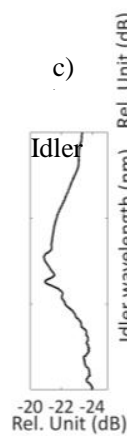

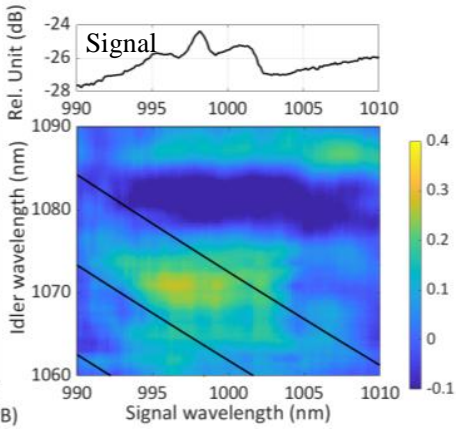

Fig. 1. a) FWM bands detected with an OSA (black line) and with the DFT method (red and blue lines). The averaged spectrum (red line) of 500 single shots (blue lines) are displayed. b) Spectral correlation map of the full spectrum. The black dashed squares correspond to the correlation between the pump and the FWM bands while the black square shows the correlation between the two bands. c) Spectral correlation between the bands. The black lines are plotted from the photon energy conservation law for several pump wavelengths.

\section{Conclusion}

We have shown that the DFT method can be used to infer the origin of the FWM within the pump from the spectral correlation between side bands. This technique brings significant new information such as the spectral distribution of parametric gain, which cannot be obtained from a standard spectrometer. We believe that it will be of prime interest for the development of fiber amplifiers supporting a very broad bandwidth [1].

\section{Acknowledgments}

ANR projects (ANR-16-CE2460009, ANR-17-EURE-0002, ANR-10-IDEX-03-02) and Bourgogne-Franche-Comté Council (SUM Project)

\section{References}

[1] C Fourcade-Dutin, O Vanvincq, A Mussot, E Hugonnot and D Bigourd, JOSA B 32, 1488 (2015)

[2] O Vanvincq, C Fourcade-Dutin, A Mussot, E Hugonnot and D Bigourd, JOSA B 32, 1479 (2015)

[3] D. Bigourd, L. Lago, A. Mussot, A. Kudlinski, J.F. Gleyze and E. Hugonnot, Opt. Lett. 35, 3840 (2010)

[4] K. Goda, B. Jalali, Nat. Photonics 7, 102 (2013)

[5] C. Fourcade-Dutin, A. Imperio et al. Photonics 6, 20 (2019)

[6] P. Béjot, J. Kasparian, E. Salmon, R. Ackermann, J.-P Wolf, Appl. Phys. B 87, 1 (2007) 